\title{
Splenic Abscess Caused by Brucellosis and Its Management: A Case Report of a Rare Clinical Entity with a Brief Review of the Literature
}

\author{
Shahram Habibzadeh, ${ }^{1}$ Moharram Aghabalaii, Jafar Mohammad Shahi, ${ }^{1}$ and Nasrollah Maleki ${ }^{2,}$ \\ ${ }^{1}$ Department of Infectious Disease and Tropical Medicine, Imam Khomeini Hospital, Ardabil University of Medical Sciences, Ardabil, IR Iran \\ ${ }^{2}$ The Persian Gulf Tropical Medicine Research Center, Department of Endocrinology, Bushehr University of Medical Sciences, Bushehr, IR Iran \\ "Corresponding author: Nasrollah Maleki, MD, The Persian Gulf Tropical Medicine Research Center, Department of Endocrinology, Bushehr University of Medical Sciences, \\ Bushehr, IR Iran. Tel: +98-9163057715, Fax: +98-4515510057, E-mail: malekinasrollah@yahoo.com
}

Received 2016 May 22; Revised 2016 December 31; Accepted 2017 January 01.

\begin{abstract}
Introduction: Brucellosis is one of the most common worldwide zoonotic and still remains endemic in many developing countries including Iran. Splenic abscess is an extremely rare complication of brucellosis. Here we describe the first reported case of splenic abscess due to brucellosis from Iran.

Case Presentation: In June 2014, a 17-year-old woman was admitted to the division of infectious diseases at the Imam Khomeini hospital, Ardabil University of Medical Science, Ardabil, Iran, with complaints of fever, nausea, sweating, headache, anorexia, and abdominal pain during the previous 2 months. Abdominal computed tomography (CT) revealed hypodense lesion within the spleen. Serum antibody tested positive at a dilution of 1:1280 by the Standard Tube Agglutination test (SAT), while blood culture yielded negative results. A diagnosis of splenic abscess due to brucellosis was made and started on streptomycin plus doxycycline and rifampin for 6 weeks. Two days after the initiation of the treatment, hemophagocytic syndrome occurred, which was controlled by oral prednisone. She was followed up in the outpatient department and was given further oral antibiotic treatment. After 2 months of treatment, CT results showed complete resolution of splenic abscess.

Conclusions: Splenic abscess due to brucellosis should be considered in differential diagnosis of patients who have complaints such as fever, sweating, and abdominal pain. The conservative approach of using antibiotics alone without surgical intervention can be successful in the treatment of splenic abscess due to brucellosis.
\end{abstract}

Keywords: Brucellosis, Abscess, Spleen, Therapeutics

\section{Introduction}

Brucellosis is a zoonotic infection, which is one of the economic and public health problems worldwide, especially in developing countries (1). In endemic areas, when dealing with patients complaining of night sweats, fever, chills, anorexia, arthralgia, and weakness associated with normal white blood cell counts and anemia, brucellosis should be placed at the top of the list of differential diagnosis and patients should be evaluated for brucellosis serological assay (2). Acute brucellosis can affect any organ system. Approximately $50 \%$ of patients have gastrointestinal complaints and primarily dyspepsia, although, abdominal pain from hepatic abscesses may occur. Gastrointestinal involvement can be present with clinical hepatitis. Constipation, diarrhea, and vomiting may occur. Rarely, other manifestations such as hepatic or splenic abscess, colitis, ileitis, cholecystitis, pancreatitis, and spontaneous peritonitis have been reported (3). The abscess can serve as a source of bacteremic seeding.

Splenic abscess is a rare entity, with a relative frequency between 0.05 and $0.7 \%$ (4). It should be noted that the mortality rate associated with splenic abscess is still high, up to $47 \%$, and appropriate management can lower mortality to less than $10 \%$ (5). Splenic abscess due to brucellosis is a rare complication of brucellosis and only 28 cases have been reported in the literature review. Park et al. (6) described a report of the first patient with Brucella endocarditis with splenic abscess in Korea. Deveer et al. (7) reported a case of splenic abscess caused by brucellosis in a 21-year-old man, which antibiotic therapy without surgical intervention, was successful. A case reported by McPhillips et al. (8) stated that a splenectomy was required due to splenomegaly and scrotal inflammation, subordinate to a multibacterial splenic abscess. Parande et al. (9) reported a case regarding a child with splenic abscess triggered from Brucella melitensis biotype 1 with an acute infection was effectively treated with solitary antibiotics. Colmenero et al. (10) described 7 cases, 4 hepatic and 3 splenic, of chronic hepatosplenic abscesses.

The beginning symptoms in every case was deceptive and the diagnostic postponement substantial. The cases presented granulomas with central necrosis, a polymorphic infiltrate, few giant cells and peripheral fibrosis. In all

Copyright ( $)$ 2017, Infectious Diseases and Tropical Medicine Research Center. This is an open-access article distributed under the terms of the Creative Commons Attribution-NonCommercial 4.0 International License (http://creativecommons.org/licenses/by-nc/4.0/) which permits copy and redistribute the material just in noncommercial usages, provided the original work is properly cited. 
6 cases the Bruella PCR-assay of the tissue or the pus sample was affirmative, where as the analytic yield with conventional microbiologic techniques was poor. Conservative therapy with antibiotics, either by itself or combined with percutaneous drainage, was unsuccessful in all cases, so that in hepatosplenic abscesses, the treatment of choice should be medical-surgical.

To the best of our knowledge, this is the first reported case of splenic abscess due to brucellosis from Iran, which was treated successfully with antibiotic therapy alone. A literature search of the PubMed database was performed for articles that have been published in the past 50 years for keywords referring to splenic abscess and brucellosis.

\section{Case Presentation}

In June 2014, a 17-year-old woman with complaints of fever, nausea, sweating, headache, anorexia, abdominal pain, and $6 \mathrm{~kg}$ weight loss during the previous 2 months was admitted to the division of infectious diseases at the Imam Khomeini hospital (which is a 386-bed, specialized, governmental, and referral hospital), Ardabil University of Medical Sciences, Ardabil, Iran. She had history of a cesarean section for 6 months prior to admission. The patient was living in a rural area and was working as a farmer. She had a history of continuous contact with goats and sheep. On admission, she was afebrile and all vital signs were stable. On examination, we found only splenomegaly and tenderness in the left upper quadrant of the abdomen.

The results of the laboratory tests are shown in Table 1. Antinuclear antibody (ANA Screen ELISA Kit, BioSupply Ltd., BD18 4LD, UK.), rheumatoid factor (RF ELISA Kit, Aida GMBH, Germany), anti-double stranded DNA antibody (Anti-dsDNA ELISA Kit, Alpha Diagnostic Intl. Inc., Texas, USA), Anti-cardiolipin antibodies (Anti-Cardiolipin ELISA kit, Biocompare, CA 94080 USA), and lupus anticoagulant (Lupus Anticoagulant ELISA Kit, MyBioSource, CA 92195-3308 USA) were all negative. A tuberculin skin test was negative. Three sets of blood cultures were taken before antibiotic administration; the cultures remained negative. Sputum and urine specimens that were taken for culture also tested negative after an incubation period of 7 days.

Chest X-ray was normal. Transthoracic echocardiography was performed, which no vegetation was reported. Abdominal computed tomography (CT) revealed splenomegaly and peripheral hypodense lesion within the spleen (measuring $23 \times 19 \times 24 \mathrm{~mm}$ ) (Figure 1). In our laboratory, serum antibody tested positive at a dilution of 1:1280 by the standard tube agglutination test (SAT) and at a dilution of 1:640 by the tube agglutination test using 2mercaptoethanol (2ME).
Table 1. The Results of Laboratory Tests

\begin{tabular}{|c|c|c|}
\hline Test & Patient & Normal Ranges \\
\hline $\begin{array}{l}\text { White blood cell } \\
\text { (WBC), per } \mathrm{mm}^{3}\end{array}$ & 9,700 & 4,500 to 10,000 \\
\hline \multirow{2}{*}{$\begin{array}{l}\text { Hemoglobin (Hb), } \\
\text { gr/dL }\end{array}$} & \multirow{2}{*}{10.7} & Male: 13.5 to 17.5 \\
\hline & & Female: 12.0 to 15.5 \\
\hline Platelets count, per $\mu \mathrm{L}$ & 317,000 & 150,000 to 450,000 \\
\hline $\begin{array}{l}\text { Erythrocyte } \\
\text { sedimentation rate } \\
\text { (ESR), mm/hour }\end{array}$ & 25 & 0 to 22 \\
\hline \multirow{2}{*}{$\begin{array}{l}\text { Aspartate } \\
\text { aminotransferase } \\
\text { (AST), IU/L }\end{array}$} & \multirow{2}{*}{188} & Males: 6 to 34 \\
\hline & & Females: 8 to 40 \\
\hline $\begin{array}{l}\text { Alanine } \\
\text { aminotransferase } \\
\text { (ALT), IU/L }\end{array}$ & 58 & 7 to 56 \\
\hline $\begin{array}{l}\text { Alkaline phosphatase } \\
\text { (ALP), IU/L }\end{array}$ & 156 & 44 to 147 \\
\hline $\begin{array}{l}\text { Lactate } \\
\text { dehydrogenase (LDH), } \\
\text { IU/L }\end{array}$ & 1,369 & 250 to 500 \\
\hline Total bilirubin, mg/dL & 1.2 & 0.3 to 1.9 \\
\hline
\end{tabular}

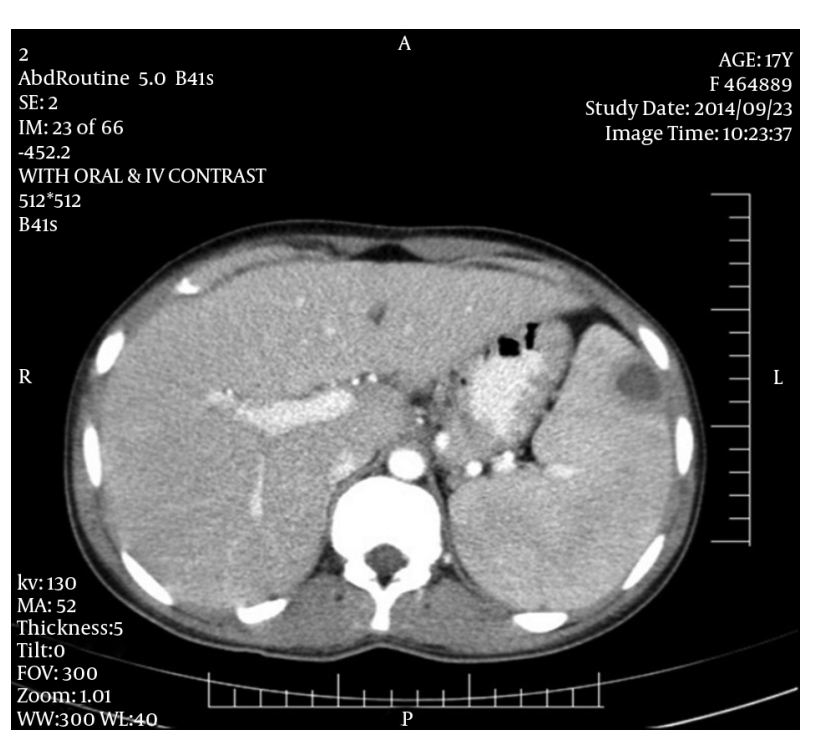

Figure 1. Abdominal Computed Tomography Showed Hypodense Lesion Within the Spleen

The patient was thought to have splenic abscess due to brucellosis and was started on doxycycline, $100 \mathrm{mg}$ orally twice daily for six weeks, plus streptomycin $1 \mathrm{~g}$ intramuscularly once daily for the first 14 to 21 days. Two days after the initiation of the treatment, a combination of fever (temperature, $38.8^{\circ} \mathrm{C}$ ), pancytopenia (hemoglobin, $7.7 \mathrm{~g} / \mathrm{dL}$; 
leukocytes, $2,500 / \mathrm{mm}^{3}$; platelets, $\left.111,000 / \mathrm{mm}^{3}\right)$, hypertriglyceridemia (triglyceride, $440 \mathrm{mg} / \mathrm{dL}$ ), increased serum ferritin $(840 \mathrm{mg} / \mathrm{L}$ ), and liver dysfunction (AST, $301 \mathrm{IU} / \mathrm{L}$; ALT, $126 \mathrm{IU} / \mathrm{L}$ ) occurred. A bone marrow biopsy revealed a normocellular marrow and macrophages phagocytizing blood cells, indicating the presence of hemophagocytic syndrome (Figure 2). Based on the authors' experiences, oral prednisone (50 $\mathrm{mg}$ daily) was added to the previous treatment. Nine days after starting prednisone, fever, pancytopenia, and liver dysfunction recovered, and prednisone was discontinued. She was followed up in the outpatient department and was given further oral antibiotic treatment of doxycycline $100 \mathrm{mg}$ twice daily, plus rifampicin $300 \mathrm{mg}$ twice daily. After 2 months of treatment, CT results showed complete resolution of splenic abscess.

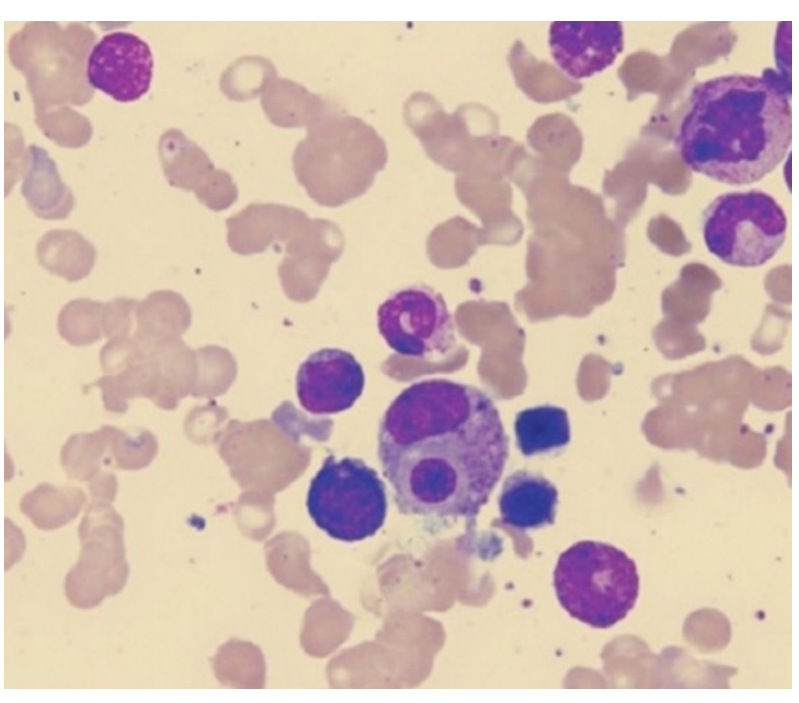

Figure 2. A Bone Marrow Biopsy Revealed a Normocellular Marrow and Macrophages Phagocytizing Blood Cells, Indicating the Presence of Hemophagocytic Syndrome.

\section{Discussion}

Brucellosis can affect almost any part of the body, including the gastrointestinal tract. In some cases, gastrointestinal symptoms may be the only presenting manifestation of the disease. These complaints can range from mild symptoms such as diarrhea and vomiting, to more serious complications such as diffuse granulomatous hepatitis, peritonitis, intestinal obstruction, colitis, pancreatitis, acute cholecystitis, and hepatic or splenic abscess. Early diagnosis and treatment of this type of presentation of brucellosis is very important because many complications can be prevented with early diagnosis and treatment (11).
Splenic abscess due to acute brucellosis is a rare entity with an incidence of $2 \%-3 \%$, even in the largest case series $(10,12)$. The definitive diagnosis of brucellosis is confirmed by isolation of a brucella species from blood, bone marrow, or other tissues. In the absence of bacteriologic confirmation, serological tests can help to diagnosis of brucellosis. The serum agglutination test is the most widely used to measure the total quantity of brucella agglutinating antibodies (13).

In addition, when using serology, our interpretation must be more cautious and not only discard patients with a serologic titer of $1 / 40$. It is proposed that equivocal or negative serological tests, with strong clinical suspicion for brucellosis, ELISA test can be recommended as the next step (14). Multiplex polymerase chain reaction (PCR) assay is a rapid and sensitive method for the diagnosis of brucellosis in comparison with the SAT. However, it is more accurate when combined with conventional methods (15).

Diagnosis and localization of the splenic abscesses due to brucellosis are relatively easy with the use of ultrasonography and computed tomography imaging. In a study done by Heller and colleagues (16), 1.2\% of patients were diagnosed with brucellosis and showed signs of hepatosplenic abscesses. This mainly originated from Brucella melitensis.

They suggested two general imaging patterns of hepatosplenic abscess due to brucellosis: (1) Characteristics of the first pattern included, independent abscesses that involved the liver, which was more frequent than the spleen, while also showing characteristics of central calcifications, (2) the second pattern was characterized by multiple smaller abscesses, lack of calcifications, and frequent spleen involvement.

Uncomplicated brucellosis infections need to be treated with streptomycin and doxycycline or gentamicin plus doxycycline or doxycycline plus rifampin for 45 days (17). Treatment protocol of problematic brucellosis (endocarditis, meningitis) has no constant agreement, however, 3 anti-Brucella drugs for 3 months is customarily used (18). In addition, the best option for treatment of splenic abscess due to brucellosis has not been clearly identified. Treatment with antibiotics alone appear to be successful only in the early stages of splenic abscess when there is no calcification in the lesions. A therapeutic approach in the early stages, with the use of antibiotic therapy alone may be an initial option. However, prolonged treatment over several months may be needed and careful follow-up is necessary because the complete cure of the disease cannot be guaranteed. The combination of medical and surgical treatment should be considered in patients when splenic abscess does not respond to antibiotic treatment (19). However, Del Arco et al. (20) suggested that surgical 
treatment must be considered in all patients with splenic abscess due to Brucella infection.

To summarize the english language literature regarding splenic abscess and brucellosis, we conducted a review using a PubMed/MEDLINE search between 1959 and 2014. Furthermore, the reference lists of all acknowledged articles were assessed for further applicable resources and also the personal documentations of the authors of this review were hand-searched. Of the 28 patients with splenic abscess due to brucellosis, 18 (69.2\%) were male and 8 (30.8\%) were female (sex is not available in 2 patients). The mean age of these patients was 41.8 years (range: 3 - 80 years). Sixteen of the patients were due to Brucella melitensis, 4 were due to Brucella suis, 2 were due to Brucella abortus, and the remaining 6 patients had a negative blood culture. Another interesting point is that many patients, including 9 cases had been reported from Turkey. Antibiotic therapy alone was required in 15 (53.8\%) patients; the remaining patients were treated with antibiotic and splenectomy.

In conclusion, splenic abscess due to brucellosis should be considered in the differential diagnosis of patients who have complaints such as fever, sweating, and abdominal pain. Although the recommended treatment for splenic abscess due to brucellosis remains controversial, there is consent that treatment with antibiotics alone should be administered prior to surgery in the early stages. Splenectomy should be considered in patients when splenic abscess does not respond to antibiotic treatment.

\section{Footnotes}

Authors' Contribution: Shahram Habibzadeh and Nasrollah Maleki designed the study and were responsible for the overall study management. Shahram Habibzadeh, Moharram Aghabalaii, Jafar Mohammad Shahi and Nasrollah Maleki prepared the manuscript. All authors approved the final version of the manuscript, and agreed for all aspects of the work.

Conflict of Interests: We declare that there is no conflict of interests regarding the publication of this paper.

Financial Disclosure: We declared that there is no financial disclosure.

\section{Funding/Support: None.}

\section{References}

1. Rubach MP, Halliday JE, Cleaveland S, Crump JA. Brucellosis in low-income and middle-income countries. Curr Opin Infect Dis. 2013;26(5):404-12. doi: 10.1097/QCO.0b013e3283638104. [PubMed: 23963260].
2. Mugahi S, Nashibi R, Alavi SM, Gharkholu S, Najafi K. Epidemiological Features, Clinical Manifestation and Laboratory Findings of Patients With Brucellosis. Arch Clin Infect Dis. 2014;9(1) doi: 10.5812/archcid.17270.

3. Pappas G, Akritidis N, Bosilkovski M, Tsianos E. Brucellosis. N Engl J Med. 2005;352(22):2325-36. doi: 10.1056/NEJMra050570. [PubMed: 15930423].

4. Chang KC, Chuah SK, Changchien CS, Tsai TL, Lu SN, Chiu YC, et al. Clinical characteristics and prognostic factors of splenic abscess: a review of 67 cases in a single medical center of Taiwan. World J Gastroenterol. 2006;12(3):460-4. [PubMed: 16489650].

5. Smyrniotis V, Kehagias D, Voros D, Fotopoulos A, Lambrou A, Kostopanagiotou G, et al. Splenic abscess. An old disease with new interest. Dig Surg. 2000;17(4):354-7. [PubMed: 11053942].

6. Park SH, Choi YS, Choi YJ, Cho SH, Yoon HJ. Brucella endocarditis with splenic abscess: a report of the first case diagnosed in Korea. Yonsei Med J. 2009;50(1):142-6. doi: 10.3349/ymj.2009.50.1.142. [PubMed: 19259361].

7. Deveer M, Sozen H, Cullu N, Sivrioglu AK. Splenic abscess due to acute brucellosis. BMJ Case Rep. 2013;2013 doi: 10.1136/bcr-2012-008485 [PubMed: 23580673].

8. McPhillips S, Friese R, Vercruysse G. Case report of rare chronic myelogenous leukemia related multibacterial splenic abscess presenting with scrotal swelling. Int J Surg Case Rep. 2014;5(12):951-3. doi: 10.1016/j.ijscr.2014.10.069. [PubMed: 25460444].

9. Parande AM, Mantur BG, Kore M, Palled E. Splenic Abscess due to Brucella Melitensis - A Rare Pediatric Complication. J Lab Physicians. 2010;2(2):105-8. doi:10.4103/0974-2727.72212. [PubMed: 21346907].

10. Colmenero Jde D, Queipo-Ortuno MI, Maria Reguera J, Angel SuarezMunoz M, Martin-Carballino S, Morata P. Chronic hepatosplenic abscesses in Brucellosis. Clinico-therapeutic features and molecular diagnostic approach. Diagn Microbiol Infect Dis. 2002;42(3):159-67. [PubMed: 11929686].

11. Aziz S, Al-Anazi AR, Al-Aska AI. A review of gastrointestinal manifestations of Brucellosis. Saudi J Gastroenterol. 2005;11(1):20-7. [PubMed: 19861843].

12. Ariza J, Pigrau C, Canas C, Marron A, Martinez F, Almirante B et al. Current understanding and management of chronic hepatosplenic suppurative brucellosis. Clin Infect Dis. 2001;32(7):1024-33. doi: 10.1086/319608. [PubMed: 11264030].

13. Vallejo JG, Stevens AM, Dutton RV, Kaplan SL. Hepatosplenic abscesses due to Brucella melitensis: report of a case involving a child and review of the literature. Clin Infect Dis. 1996;22(3):485-9. [PubMed: 8852967].

14. Bashiri H, Sayad B, Madani SH. Study of the Assimilation Rate of Immunoenzymatic Tests and Traditional Serological Methods in the Diagnosis of Human Brucellosis. Jundishapur J Microbiol. 2013;6(4) doi: $10.5812 /$ jjm.4828.

15. Lari Rastegar A, Karimi A, Fallah F, Angoti G, Sanaei A, Azimi L. The Ef ficacy of multiplex PCR in comparison with agglutination and ELISA in diagnosis of human Brucellosis. Iran J Clin Infect Dis. 2011;6.

16. Heller T, Belard S, Wallrauch C, Carretto E, Lissandrin R, Filice C, et al. Patterns of Hepatosplenic Brucella Abscesses on Cross-Sectional Imaging: A Review of Clinical and Imaging Features. Am J Trop Med Hyg. 2015;93(4):761-6. doi: 10.4269/ajtmh.15-0225. [PubMed: 26283749].

17. Roushan MR, Ahmadi SA, Gangi SM, Janmohammadi N, Amiri MJ. Childhood brucellosis in Babol, Iran. Trop Doct. 2005;35(4):229-31. doi: 10.1258/004947505774938693. [PubMed:16354479].

18. Buzgan T, Karahocagil MK, Irmak H, Baran AI, Karsen H, Evirgen O, et al. Clinical manifestations and complications in 1028 cases of brucellosis: a retrospective evaluation and review of the literature. Int I Infect Dis. 2010;14(6):e469-78. doi: 10.1016/j.ijid.2009.06.031. [PubMed: 19910232].

19. Yilmaz M, Arslan F, Baskan O, Mert A. Splenic abscess due to brucellosis: a case report and a review of the literature. Int J Infect Dis. 2014;20:68-70. doi: 10.1016/j.ijid.2013.11.010. [PubMed: 24433982]. 
20. Del Arco A, De La Torre-Lima J, Prada JL, Aguilar J, Ruiz-Mesa JD, Moreno F. Splenic abscess due to Brucella infection: is the splenectomy necessary? Case report and literature review. Scand J Infect
Dis. 2007;39(4):379-81. doi: 10.1080/00365540600978930. [PubMed: 17454910]. 